\title{
El Español como Lengua Extranjera en los Estudios de Humanidades: Integración de Elementos Lingüísticos y Socio-Culturales a través de la Fraseología Española
}

\author{
Maria Jesús Leal, Universidad de Hamline, Minnesota, USA
}

Resumen: El desarrollo de la competencia comunicativa en una lengua extranjera y el estudio de los fenómenos lingüisticos a través del análisis del discurso y de la pragmática son dos pilares fundamentales en la formación de estudiantes que eligen las Humanidades como ámbito para sus estudios universitarios. En el marco de la adquisición de una segunda lengua con finalidades académicas y didácticas esta comunicación presenta una refexión desde la docencia sobre la adquisición de español como vehículo para el conocimiento de la realidad multicultural y diversa del mundo hispanohablante reflejada en la fraseología y en el discurso oral.

Palabras Clave: fraseología, idiomaticidad, fijación, lenguaje metafórico, español como lengua extranjera, cultura

Abstract: The development of the communicative competence in a foreign language and the study of the linguistic phenomena through the analysis of the pragmatics of discurse is an essential base in the study of Spanish and its role within the Humanities. In the field of the acquisition of Spanish as a second language with academic and didactic purposes, this article presents a reflection on the acquisition of Spanish as a means to understand the multicultural and diverse reality of the Hispanic world reflected in the phraseology and oral discourse. The purpose of this article is to provide professors of Spanish and students with an instrumental knowledge on Spanish idiomaticity in order for them to be proficient in the lingusitic and sociocultural aspects of the Spanish language.

Keywords: phraseology, idiomaticity, equivalence, multiculturality, diversity

\section{Introduccion}

$\mathrm{L}$

A FRASEOLOGÍA ES un ámbito multidisciplinar difícil de delimitar en el que confluyen la semántica y la pragmática del discurso, la cultura y la estilística. A partir de la importancia cultural que tiene la fraseología de toda lengua, se analiza aquí el papel que juegan estas combinaciones fijas e idiomáticas en la enseñanza del español como lengua extranjera, haciendo referencia explícita a las dificultades que entraña el tratamiento del significado metafórico de las unidades fraseológicas en el aula de E/LE. Al mismo tiempo este trabajo explora el origen y la vertiente cultural que poseen estas manifestaciones del lenguaje popular y coloquial para desarrollar el conocimiento y contraste de culturas diferentes.

Mi objetivo es plantear un método que facilite al estudiante el aprendizaje de la fraseología española. En este sentido, la lingüística cognitiva recurre al contraste fraseológico y trata de comparar las unidades fraseológicas en español y la lengua nativa de los aprendices para

Revista Internacional de Ciencias Humanas

Volumen 1, Número 1, www.lascienciashumanas.com, ISSN 2530-4526

(C) Global Knowledge Academics, Maria Jesús Leal, Todos los Derechos Reservados

Permisos: soporte@gkacademics.com

Republicado de Revista Internacional de Humanidades 1(1), 2012 (pp. 43-52) 
buscar y reconocer los esquemas metafóricos que estas dos lenguas comparten. Esto es efectivo porque la transferencia lingüística de la lengua nativa a la lengua meta facilita y agiliza el proceso de aprendizaje de estas variadas estructuras combinadas.

\section{Español como Lengua Extranjera en los Estudios de Humanidades. Integración de Elementos Lingüísticos y Socio-Culturales a través de la Fraseología Española}

Existe una parte de la cultura lingüística que contiene expresiones con un significado propio no composicional, que se repiten siempre igual, en contextos o situaciones similares. Son la expresión de la parte más viva e idiosincrásica de una lengua. Son esas formas de decir que se crean cada día y que pasan a formar parte del conocimiento colectivo. Estas expresiones pertenecen a un hablante que maneja su propia lengua, integrada dentro de su cultura y que diferencian a los estudiantes de español como lengua extranjera, quienes no comprenden el significado de las unidades fijas e idiomáticas a pesar de haber dedicado semestres al estudio de la lengua española. Estos dichos, modismos, expresiones idiomáticas, metáforas culturales, como quiera que queramos denominarlas, se aprenden de boca en boca, en la calle, en familia y con los amigos. Las hemos escuchado siempre porque forman parte del conocimiento enciclopédico de una comunidad de hablantes. Estas expresiones dan fe de la libertad y la capacidad para inventar, del sentido del humor y de la creatividad lingüística. Como ejemplos de unidades fraseológicas que contienen elementos culturales se pueden citar aquí: alegrarse como unas castañuelas; ser peor que la obra del Escorial; hacerse el sueco; estar entre Pinto y Valdemoro; para ti la perra gorda. Como es sabido, cualquier hablante de español peninsular conoce perfectamente el significado de estos ejemplos aunque no conozca el origen y lo sabe porque ha escuchado y utilizado estas expresiones en circunstancias parecidas a lo largo de su vida en su comunidad de hablantes.

Gran parte de la fraseología contiene lenguaje coloquial. A muchas de estas expresiones se las desplaza hacia atrás en el tiempo a una circunstancia histórica concreta como muestran los siguientes ejemplos: no se tomó Zamora en una hora ${ }^{1}$; armar la marimorena ${ }^{2}$; como deciamos ayer ${ }^{3}$, armarse la de San Quintín ${ }^{4}$. Otras unidades tienen su origen en la literatura: poderoso caballero es Don Dinero ${ }^{5}$; poner el cascabel al gato ${ }^{6}$, peor es meneallo ${ }^{7}$; des-

\footnotetext{
${ }^{1}$ El rey Sancho II no estaba de acuerdo con el reparto de la herencia y luchó por conseguir Zamora, que había heredado su hermana Doña Urraca. Sancho II, con gran esfuerzo y tozudez, logró apoderarse de Zamora después de meses de asedio y contienda. De ahí esta famosa frase que utilizamos para aconsejar paciencia y constancia para lograr los objetivos.

${ }^{2}$ Armar la marimorena surgió a raíz del pleito que en 1579 iniciaron una tabernera de la corte de Madrid y su esposo Alonso de Zayas contra María Morena por "tener cueros de vino y no querer vender". Desde entonces la usamos coloquialmente para describir una gran pelea o bronca entre varias personas.

${ }^{3}$ Como decíamos ayer es la famosa frase que utilizó Fray Luis de León al retomar sus clases en la universidad de Salamanca tras cinco años de prisón, sentencia a la que fue condenado por la Inquisición en el siglo XVI.

${ }^{4}$ Armarse la de San Quintín recuerda la victoria de Felipe II sobre los franceses en la batalla de San Quintín en la que se armó una violenta lucha. Hoy la utilizamos para describir una gran pelea.

${ }^{5}$ Poderoso caballero es don Dinero es la sentencia burlona de Francisco Quevedo. Todas las estrofas de la obra rematan con la irónica sentencia para criticar con sorna el poder del dinero y los que lo utilizan para controlar.

${ }^{6}$ Poner el cascabel al gato deriva de un cuento antiguo puesto en verso por Lope de Vega popularizado por Samaniego en su fábula: El congreso de los ratones. Su significado es el de conseguir algo difícil y que requiere mucho valor. Entre los ratones, ¿quién se atreve a poner el cascabel al gato?

${ }^{7}$ Peor es meneallo lo puso Cervantes en boca de Sancho Panza en su universal obra Don Quijote. Esta expresión significa que es mejor no hablar más de un asunto o indagar más en algo no muy agradable.
} 
cender de la pata del $\mathrm{Cid}^{8}$; o en la tradición oral: a buenas horas mangas verdes ; saber más que Lepe; quien fue a Sevilla perdió su silla. No siempre es fácil saber cuál es el origen de una expresión dadas las constantes interferencias a las que el discurso coloquial se ha sometido y a las múltiples versiones que una leyenda, un cuento o una canción puedan tener. Cualquiera que sea su origen, forman parte de la cultura y son un vehículo para expresarla y para introducir al estudiante en ella.

La importancia de la fraseología radica en su abundante utilización en conversaciones, en los medios de comunicación escrita y audiovisual. En el ámbito de español como lengua extranjera se caracterizan por la dificultad que los estudiantes de español como lengua extranjera experimentan para, en primer lugar, delimitarla y, segundo, reconocer el sentido no literal de tales expresiones. Estas unidades léxicas fijas utilizan el lenguaje metafóricamente y su significado se reconoce porque se han fijado en el uso y porque la fijación permite la descodificación. Las imágenes esquemáticas que representan las expresiones fijas e idiomáticas a menudo son metáforas complejas que rompen la formalidad habitual, se transmiten oralmente y son una herencia compartida que se repite en el espacio cultural compartido de la comunidad de hablantes.

Desde el punto de vista didáctico, es mi intención hablar de la importancia de estas expresiones en el aula de Español como Lengua Extranjera, invitar a los profesores a reflexionar sobre los conceptos culturales para desarrollar la competencia intercultural. En este sentido, la fraseología constituye uno de los principales escollos con el que se encuentra el aprendiz por lo que, de acuerdo con los distintos tipos de unidades fraseológicas existentes, habría que abordar la enseñanza de estas desde una perspectiva multidisciplinar.

Hay que tener muy presente que la lengua no es un hecho aislado, sino un instrumento social y cultural. De este modo, resulta eficaz reconocer que la competencia fraseológica de un hablante depende en gran medida del conocimiento de la cultura en la que está inmerso el sistema lingüístico que se pretende adquirir. El conocimiento de la gramática, la fonética y el léxico es esencial para dominar una lengua. Sin embargo, no se trata únicamente de asimilar los contenidos que surgen en el aula y en los manuales o de repetir funciones comunicativas sino que también debe existir un espacio para la cultura. En este sentido, hay que considerar la fraseología como una parte integrante y esencial de la realidad sociocultural.

Es bastante frecuente en los trabajos de fraseología española en el ámbito de Español como Lengua Extranjera citar la introducción del conocido Diccionario Akal del español coloquial (Ramos y Serradilla, 2000: 10-11), en la que las autoras recrean la experiencia de Mark, un estudiante de Estados Unidos quien, después de haber estudiado español con éxito durante cinco años y terminar un master de cultura y civilización españolas, se consideraba capacitado para hablar como un nativo. Decide tener una experiencia de inmersión en Madrid pero nada más llegar descubre que no entiende nada de lo que dice el taxista cuando Mark le da la dirección de la residencia: "Buenas, ¿Qué hay? ¿Por dónde cae esa residencia? Seguro que está en el quinto pino y no hay tu tía que dé con ella ". En la residencia universitaria donde se va a instalar el estudiante espera encontrar gente muy culta que hable como sus profesores y como en sus libros. Sin embargo, un joven nativo español le saluda así: “¿Qué pasa tío? ¿Tú eres el nuevo? Vamos, date prisa en elegir tu habitación, que si no te va a pillar el toro. No pongas esa cara; seguro que hacemos buenas migas, te aviso de

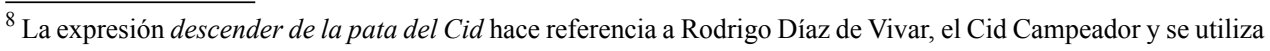
irónicamente para bajar los humos a quien se cree superior.
} 
que yo hablo por los codos y que a veces me voy por las ramas, pero yo soy buena gente. ¡Ah!, por si las moscas, lo mejor es que cierres tu puerta con llave, porque aqui hay mucho chorizo. Mark no podía creerse lo que le estaba sucediendo. Subió corriendo las escaleras para ponerse a salvo de los toros que, según su nuevo compañero, debían de estar brincando alegremente por los pasillos de la residencia. Una vez que se encerró en su habitación empezó a buscar las moscas que también debian de ser muy abundantes y seguro que enormes, ya que tanto le habian advertido. Aunque luego lo pensó mejor: ese chico debía de estar loco, él le había visto hablar por la boca, como todos los demás, pero quizá era ventrílocuo y era verdad que hablaba por los codos; pero ¿qué podía esperarse de una persona que se andaba por las ramas y que quería hacer migas? Además el chorizo era una comida muy apetecible y no entendía por qué tenía que defenderse de él. Los chorizos no andan, ¿o sí?"?.

Los estudiantes que llegan a España o a otros países hispanohablantes pueden vivir estas situaciones de confusión y perplejidad. Tal vez la cita es excesiva en la acumulación de unidades fraseológicas pero en mayor o menor medida es una realidad bastante aproximada a un discurso oral coloquial en un entorno lingüístico extranjero, que se puede dar en una residencia estudiantil, en un bar, o en cualquier lugar donde se reúne un grupo de amigos. Es raro encontrar este discurso en los manuales de español y, en general, en las aulas de español como lengua extranjera. Sin embargo, los profesores tienen la responsabilidad de enseñarlas para que los estudiantes desarrollen su competencia utilizando patrones lingüísticos y fraseológicos clasificados en funciones comunicativas conectadas con la realidad inmediata.

En el proceso de aprendizaje los diferentes tipos de unidades fraseológicas - locuciones (ser más agarrado que un chotis; a troche y moche; despedirse a la francesa), colocaciones (marcar un gol; soltero empedernido) y enunciados fraseológicos ( y un jamón; tararí que te vi)- surgen problemas de diversa índole: demarcación, comprensión, memorización y actualización. La experiencia como docente demuestra que en el método de enseñanza y aprendizaje se debe considerar, en un alto grado, la cultura en la que está inmersa la lengua meta que los estudiantes pretenden adquirir. En muchas ocasiones es necesario poder ofrecer una explicación sobre las causas que motivaron una unidad fraseológica, como el de aquellas cuyo origen se halla en algún hecho histórico o social concreto. De este modo el aprendiz será capaz de realizar una correcta decodificación y posterior codificación de las expresiones idiomáticas así como un correcto uso en el registro adecuado.

Cualquier hablante, cuando hace uso de su lengua, necesariamente tiene que tener presente, aunque sea de modo inconsciente, el contexto situacional. Es decir, debe practicar una adecuación pragmática en el acto lingüístico. Tal vez las unidades fraseológicas necesiten especial atención ya que algunas tienen una aplicación bastante restringida, como por ejemplo: separar la s churras de las merinas. Por ello, el docente debe documentar suficientemente al estudiante para que el incorrecto uso de determinadas expresiones fijas no revele su falta de competencia lingüística ante determinadas circunstancias. Piénsese, por ejemplo, en la unidad fraseológica Santa R ita lo que se da no se quita cuyo origen es el siguiente: una doncella le pidió a Santa Rita, patrona de los imposibles, un buen novio. A los pocos días Santa Rita le obsequió con un novio que no fue tan bueno como la doncella esperaba porque desapareció de la misma forma milagrosa. La doncella se plantó delante de la santa y le dijo: "Santa Rita, Rita, Rita, lo que se da ya no se quita" ${ }^{10}$. No se sabe si el novio regresó pero el

\footnotetext{
${ }^{9}$ Ramos y Serradilla (2000)

${ }^{10}$ Iribarren (1994)
} 
dicho permanece y su uso se ha extendido a todo tipo de situaciones en las que alguien da algo y después desea recuperarlo. Si podemos hablar a nuestros estudiantes sobre el origen de las unidades fraseológicas que contienen elementos socioculturales, sin duda las aprenderán mejor, con menos esfuerzo y de una forma algo más permanente.

Sin olvidar el conocimiento pragmático, y como ha señalado Ruiz Gurillo (1994), es necesario tener en cuenta que "las unidades fraseológicas son difíciles de traducir en abstracto, al margen de un texto concreto, pues se relacionan estrechamente con un hecho histórico o con una situación específica, y esto repercute en el aprendizaje". Por su parte, Koike (2001: 210) ha destacado que esto sucede con especial intensidad en las colocaciones que llama "culturales". Es decir, la lengua española, como otras, posee colocaciones culturales propias, únicas, que no tienen correspondencia con las demás lenguas. El ejemplo más claro de unidades fraseológicas culturales del español lo tenemos en las expresiones que provienen del mundo de los toros. Este contenido cultural hace que los españoles tengan problemas para traducir a otros idiomas la colocaciones que proceden de la fiesta taurina, a saber: $a$ toro pasado; estar para el arrastr e; ver los toros desde la barrer a; agarrar al toro por los cuerno s; estar al qu ite; salir por la puerta grande; ponerse el mundo por montera; lanzarse al ruedo; cortarse la coleta, que probablemente se expresen mediante una combinación libre en otros idiomas. Entre los ejemplos citados la locución cortarse la coleta es un símil que alude al hecho de retirarse de los ruedos y como símbolo el torero se corta la coleta. Estas expresiones ya no pertenecen única y exclusivamente a la plaza de toros o a la sección de la fiesta de los toros que aparecen en los periódicos. Son expresiones que utilizamos todos los hablantes nativos de español en situaciones metafóricamente parecidas. De este modo, el docente debe tener en cuenta el entorno cultural en el que cobran vida estas combinaciones de palabras y explicarlo en el aula. El objetivo es facilitarle el aprendizaje al estudiante y ayudarle a comprender que es necesario despojarse, en parte, de su cultura y sumergirse en la nueva para el dominio lingüístico de la frasología.

En cuanto a otros tipos de unidades fraseológicas, como las locuciones o las paremias, la necesidad del conocimiento cultural es, con toda seguridad, mucho más palpable. No es extraño encontrar unidades para las que se hace necesario remontarnos a un hecho histórico del pasado, a una situación real o ficticia, o incluso, a una anécdota si queremos explicar su significado y su origen. Sin embargo no deseo ir al pasado histórico de España, sino al presente y los recientes eventos del 15 de mayo de 2011 en la Puerta del Sol de Madrid y las plazas de las ciudades españolas. Me refiero al Manifiesto "DEMOCRACIA REAL YA", una manifestación que ha tenido lugar en las diferentes ciudades de España en la que un grupo de jóvenes creativos, críticos, inteligentes e INDIGNADOS decide expresar su descontento y generar un debate de calado en la sociedad española. Esta ha sido la mayor protesta cívica del nuevo siglo en España, un mayo del 2011 absolutamente pacífico y no violento. En una publicación titulada New Directions in the Humanities, quiero dedicar espacio en mi artículo a reflexionar, desde el punto de vista lingüístico, sobre estos acontecimientos recientes y presentes. El contexto es el siguiente: los jóvenes que suscriben el manifiesto: DEMOCRACIA REAL YA se reunieron en plazas de las diferentes ciudades españolas y de otros países para expresar su preocupación e indignación por el panorama político, social y económico. En este trabajo me interesa especialmente el discurso de estos manifestantes pacíficos, creativos social y lingüísticamente, en su mayoría jóvenes. Para contextualizar cito textualmente su propia descripción "Unos nos consideramos más progresistas, otros más conservadores. Unos creyentes, otros no. Unos tenemos ideologías bien 
definidas, otros nos consideramos apoliticos... Pero todos estamos preocupados e indignados por el panorama político, económico y social que vemos a nuestro alrededor, $p$ or la corrupción de los políticos, empresarios, banqueros... Por la indefensión del ciudadano de a pie". 11

En este contexto, vamos a prestar atención a las expresiones que han ido acuñando y con las que se ha identificado a estos jóvenes quienes se han hecho oír a través de los medios de organización social y de las tecnologías disponibles hoy día. Su discurso, desde la Puerta del Sol es:

1. Aqui estamos, aguantando de sol a sol

2. Aqui estamos, aguantando el sol como se puede

3. Estamos desolados

4. Estamos en la plaza de

5. No podemos apretarnos el cinturón y bajarnos los pantalones al mismo tiempo

6. Poco pan para tanto chorizo

La unidad fraseológica aqui estamos aguantando de sol a sol o aqui estamos aguantando el sol como se puede son expresiones que han utilizado para manifestar el esfuerzo y la constancia de su protesta en la Puerta del Sol. Estas expresiones evocan otras léxicamente opuestas: ag uantando el temporal / aguantando el chaparrón, algo que por desgracia se oye mucho últimamente; la plaza de la solución como se ha bautizado este nuevo Estado, y estamos desolados incluyen un juego de palabras con sol como base y de connotación positiva o negativa, según se mire. Lo más llamativo de no podemos apretarnos el cinturón y bajarnos los pantalones al mismo tiempo así como poco pan para tanto chorizo es la ironía que contiene y es que precisamente la ironía es una de las características esenciales de la fraseología. Todas ellas dan fe de la creatividad, la fuerza expresiva y el gran efecto que tiene la manipulación de la fraseología. Entender, por tanto, un fraseologismo y poder utilizarlo implica entonces un acercamiento a la cultura del país en el que se habla la lengua que el aprendiz está en proceso de aprender y dominar. En el aprendizaje de estas unidades se puede observar una doble perspectiva que redunda positivamente en la inmersión del aprendiz en la nueva comunidad lingüística y la cultura en la que ésta lengua vive. No solo resultan necesarias las explicaciones históricas, literarias, o de sabiduría popular para obtener una adecuada competencia lingüística de una de estas expresiones, sino que, además, con ellas se puede engrosar el conocimiento cultural como he ejemplificado anteriormente en una realidad actual. En este sentido, la manipulación fraseológica es fascinante en expresiones como estamos desolados (que se aplica a situaciones de desolación e impotencia) aquí estamos de sol a sol y las otras mencionadas quedan fijadas por el momento. No se puede saber si permanecerán o no en la lengua española. Lo que sí está claro es que aporta una gran información cultural y social al alumno no nativo de español.

Los caminos por los que se adentran los estudiantes y los profesores frente a la tarea de aprender y explicar esta parte del lenguaje son interesantísimos pero nada fáciles. El camino resulta más dificultoso cuando el estudiante se ve sometido a una situación de manipulación discursiva de unidades fraseológicas. Lo cierto es que según las conclusiones de Ruiz Gurillo

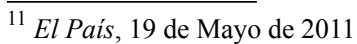


$(1997)^{12}$ la manipulación creativa de la fraseología es frecuente, no es ocasional, no es una incorrección, no aparece aisladamente sino integrada en textos de esta manera. Estas modificaciones contextuales dependen de la estabilidad semántica y formal que caracterizan a estas unidades, y también del conocimiento previo de las unidades originales que sirven como base. Es relativamente fácil para un hablante nativo, es realmente difícil e improbable que un estudiante extranjero pueda identificar, interpretar y utilizar una unidad fraseológica en la que se da un caso de manipulación fraeseológica creativa ${ }^{13}$. Las fases identificativa e interpretativa son más lentas por la deformación de las formas canónicas, es decir, de la unidad fraseológica original. La variabilidad de las unidades fraseológicas, lejos de ser algo excepcional, constituye una de sus características inherentes y propias. Esta variabilidad puede darse de dos formas diferentes aunque relacionadas: variabilidad estable y variabilidad ocasional. La primera se refiere a variaciones, la segunda se refiere a modificaciones. En ambos casos, el estudiante y el traductor se enfrentan a la dificultad de dar cuenta de una infinidad de concentraciones semántico-pragmáticas de complicada resolución durante el proceso de aprendizaje.

El hablante nativo ha escuchado desde siempre este tipo de expresiones y las ha asimilado sin preguntarse por su origen. Puede que en algún momento si se haya planteado la cuestión con una unidad nueva o fuera de contexto si esta carece de transparencia. Independientemente del origen o la motivación que dio lugar a la expresión fijada con toda seguridad el hablante conocerá su significado puesto que lo ha adquirido a lo largo del desarrollo de su competencia lingüística. Sin embargo, para el aprendiz de L2 resulta esencial conocer el origen o la motivación de la unidad fraseológica, en la medida en que le puede ayudar a buscar cierta lógica, al tiempo que contribuye a salvar el escollo que plantean la idiomaticidad y la fijación, la agramaticalidad, la no composicionalidad del significado, las palabras diacríticas y las imágenes, muchas veces extrañas, que evocan las expresiones.

En este sentido, además de indicaciones sobre el registro de cada unidad fraseológica, o informaciones de uso gramatical o pragmático, el profesor deberá proporcionar al alumno la explicación del origen de la unidad fraseológica junto con su inserción en contextos que ilustren su uso ${ }^{14}$. Todo esto, sin lugar a dudas, supone un mayor esfuerzo por parte del docente que no solo tiene que atender a los conocimientos puramente lingüísticos, sino también a los de índole histórica, literaria, o según los ejemplos elegidos para ilustrar esta comunicación, índole política y social. Sin embargo, el esfuerzo vale la pena porque este enfoque multidisciplinar asegura el éxito en el aula y fuera de ella. Los programas de lengua y cultura que en algunas universidades se imparten se abordan materias como la historia, la música, el cine, las artes e incluso el folclore, junto con las asignaturas específicas del ámbito lingüístico. El objetivo del docente debe ser, por tanto, el de proporcionar al estudiante una cierta competencia fraseológica. Lo realmente interesante es que el alumno tenga la sensación de que, de forma imperceptible, se está sumergiendo en la cultura transitoria de adopción y que, de alguna manera, va adquiriendo esas expresiones tan motivadoras del aprendizaje en el que la lengua extranjera y la cultura se interrelacionan de forma inevitable.

\footnotetext{
$\overline{12}$ Ruiz Gurillo (1997) "Relevancia y fraseología: La desautomatización en la conversación coloquial"

${ }^{13} \mathrm{La}$ traducción de unidades fraseológicas manipuladas ha sido objeto de estudio de autores como Delabastia (1998), Bender Berland (1999), Corpas Pastor (2000a), Zuluaga (2000-2001) y muy especialmente Labno Falecka (1995).

${ }_{14}$ Para ello contamos con trabajos como el Diccionario fraseológico documentado del español actual de Manuel Seco et al. (2004), que ofrece las unidades fraseológicas insertadas textos y contextos.
} 
La metáfora puede manifestarse en todo tipo funciones comunicativas y de situaciones orales, mayormente. Algunas metáforas son básicamente culturales y propias de cada lengua. Los ejemplos "como decíamos ayer", "a toro pasado", "a buenas horas mangas verdes", "ideas del año catapún" "los tiempos de Maricastaña” son unidades fraseológicas idiosincrásicas, que pertenecen solo a la lengua española, cuyo origen está en la historia, la literatura y la cultura. Para éstas no se encuentran equivalencias, aunque por supuesto en cada lengua existe un modo de decir lo mismo. En muchos casos las metáforas dan expresión a realidades abstractas en términos de otras más concretas. En este sentido tenemos en la lengua española un buen número de metáforas que, como muy bien dicen Lakoff y Johnson, son metáforas de la vida cotidiana. Algunos ejemplos pueden incluir contenidos religiosos: tener la edad de Cristo; colocar en un altar; meterse en un belén; pasar las de Caín; hacer algo en un verbo; llegar y besar el santo; hacer algo en menos que se santigua un cura; aparecerse la Virgen; otro gallo te cantara; terminar como el rosario de la aurora. Muchas de las semejanzas que percibimos son el resultado de metáforas convencionales, que forman parte de nuestro sistema conceptual. Las comparaciones son muy frecuentes en la fraseología y así se pueden ofrecer los siguientes ejemplos de comparaciones que hacen referencia a la cultura: vivir como un rey/como un marqués/como un señorito/como un cura; dormir como un tronco/como un lir ón/como un angelito; comer como un pajarito/como un cerdo; beber como una esponja/ como un cosaco.

El enfoque contrastivo aplicado a la enseñanza de fraseología favorece la comparación interlingüístca, ayuda al aprendiz en el descubrimiento de semejanzas y diferencias entre su lengua nativa y la que está aprendiendo, y facilita en cierta medida la contextualización de estas combinaciones fijas, idiomáticas, pluriverbales, caracterizadas por sus múltiples connotaciones. La utilidad pedagógica de recurrir a la lengua nativa es evidente y facilita la comprensión. Está claro que el contraste de expresiones idiomáticas muestra formas distintas de enfrentarnos a las mismas realidades culturales. Una reflexión de Bernal (1999:37) refiriéndose a este aspecto concreto de la fraseología: "se ha demostrado que la L 1 juega un papel importante en a adquisición y uso de las unidades fraseológicas en L2 y, en este sentido, se afirmado que los aprendices de una L2 no pueden ser vistos como un territorio fraseológicamente virgen ya que tienen almacenadas un conjunto de ellas, propias de su lengua materna, las cuales, inevitablemente, juegan un papel tanto positivo como negativo, en la adquisición de las de la L 2". De ello se desprende que contrastar las unidades fraseológicas de la lengua materna con las de la L2 puede ser de gran utilidad en el proceso de aprendizaje de la fraseología de la lengua española en este caso.

\section{Conclusión}

Los modismos desarrollan la competencia comunicativa y las tres subcompetencias lingüísitca, sociolingüísitica y pragmática e incluyen al hablante y al oyente en un espacio común, culturalmente compartido. Cuando utilizamos un modismo podemos parecer irónicos, exagerados, chistosos, convincentes, indignados. Podemos describir, saludar, despedirnos, expresar sentimientos, y muchas funciones comunicativas más. Es la fraseología un ámbito lingüístico en el que se hace más evidente la necesidad de llamar la atención a los aprendices de español sobre la gran diferencia entre qué quiere decir una palabra y qué queremos decir con una combinación fija de palabras que no tienen un significado compositivo o literal, sino idiomático. Su importancia radica en su abundante uso en las conversaciones, en los medios 
de comunicación escritos y audiovisuales, y en la dificultad que tienen los estudiantes de español como lengua extranjera de reconocer el sentido no literal de una expresión.

\section{Referencias}

Alonso, E. (1994). Cómo ser profesor y querer seguir siéndolo? Madrid: Edelsa/Edi6.

Barrios, M. (1982). Modismos y coplas de ida y vuelta. Madrid: Ediciones de la Cultura Hispánica del Instituto de Cooperación Iberoamericana.

Beltrán, M.J. y Yáñez, E. (1996). Modismos en su salsa. Madrid: Arco/ Libros.

García-Page, M. (2008). Introducción a la fraseología española. Estudio de las locuciones. Rubí. Barcelona: Anthropos Editorial.

Iribarren, J. M. (1994): El porqué de los dichos. Pamplona: Gobierno de Navarra, Departamento de Educación y Cultura.

Koike, K. (2001): Colocaciones léxicas en el español actual: estudio formal y léxicosemántico. Alcalá de Henares, Universidad.

Lakoff, G. y Johnson, M. (1980=1991). Metaphors we live be (Traducción Castalia: Metáforas de la vida cotidiana). Madrid: Cátedra.

Penadés Martínez, I. (1999). "Para un tratamiento de las expresiones fijas irónicas desde la pragmática". Pragmalinguística. 7 , 185-210.

Penadés Martínez, I. (1999): La enseñanza de las unidades fraseológicas. Madrid: Arco Libros.

Ramos, A. y Serradilla, A. (2000): Diccionario Akal del español coloquial. Madrid, Ediciones Akal.

Ruiz Gurillo, L. (1994). Algunas consideraciones sobre las estrategias de aprendizaje de las fraseología del español como lengua extranjera. En J. Sánchez Lobato, \& I. Santos Gargallo, Problemas y métodos en la enseñanza del español como lengua extranjera. Actas del IV Congreso Internacional de ASELE (pp. 141-151). Madrid: SGEL.

Ruiz Gurillo, L. (1997). "Relevancia y fraseología: la desautomatización en la conversación coloquial”. Español Actual. 68 , 21-30.

Santamaría, I. (1998): "El tratamiento de las unidades fraseológicas en la lexicografía bilingüe", Estudios de lingüística, 12, 299-318.

Seco, M., Andrés, O., y Ramos, G. (2004). Diccionario fraseológico documentado del español actual . Madrid: Aguilar Lexicografía.

Sevilla Muñoz, J. y González Rodríguez, A. (1994). La traducción y la didáctica de las expresiones idiomáticas. Equivalences. 24-2. 25-1/2 , 171-182.

Varela, F. y Kubart, H. (1994). Diccionario fraseológico del español moderno. Madrid: Gredos.

\section{Sobre el Autor}

Dr. Maria Jesús Leal

Soy profesora de español en el Departamento de Lenguas Modernas de Hamline Unversity, St Paul, Minnesota.Licenciada en Filología Inglesa en la Univesidad de Valladolid y Doctora en Lingüística Comparada (español-inglés). Mi doctorado y mi investigación actual se centra en el análisis contrastivo de la fraseología española e inglesa, con especial interés en la cara- 
REVISTA INTERNACIONAL DE CIENCIAS HUMANAS

cterística de la idiomaticidad fraseológica. Me interesa la metodología de la enseñanza de español como lengua extranjera y el enfoque multidisciplinar de su docencia incluyendo cine, cultura, música, historia y literatura. 